\title{
Eicosatetraenoic Acid n-3
}

National Cancer Institute

\section{Source}

National Cancer Institute. Eicosatetraenoic Acid n-3. NCI Thesaurus. Code C68358.

A polyunsaturated long-chain fatty acid with a 20-carbon backbone and 4 double bonds, originating from the 3rd, 6th, 9th and either the 12th or 15th positions from the methyl end. Two separate isomers can be called by this name. 